\title{
Residência Pedagógica e a formação docente em tempos de pandemia: desafios e perspectivas dos licenciandos
}

\author{
Pedagogical residency and teacher training in times of pandemic: challenges and perspectives from
} the perspective of undergraduates

Residencia pedagógica y formación docente en tiempos de pandemia: desafíos y perspectivas desde la perspectiva de los estudiantes de pregrado

\section{Resumo}

A referida pesquisa buscou conhecer as percepções de residentes vinculados ao Programa Residência Pedagógica (PRP) no âmbito do Instituto Federal do Piaú (IFPI), com ênfase aos impactos da execução do programa em cenário remoto. A pesquisa caracteriza-se como básica, de natureza observacional e abordagem quali-quantitativa. Sua realização ocorreu integralmente de forma online, utilizando-se ferramentas de comunicação digital ao contato com os residentes. A formalização da participação ocorreu através do aceite a um Termo de Consentimento Livre e Esclarecido (TCLE). Para coleta de dados, utilizou-se um questionário semiestruturado elaborado por meio da plataforma Google Forms e enviado aos participantes através do aplicativo WhatsApp. As respostas obtidas evidenciam que o PRP-IFPI (2020-2022) é muito importante para a formação profissional dos residentes, e que apesar das exigências impostas pelo ensino remoto, sua execução vem ocorrendo de forma adequada e proporcionando diversos aprendizados. Os residentes também apontam as dificuldades dos estudantes da educação básica no acesso às tecnologias digitais e internet, bem como o frequente desinteresse e pouca participação nas aulas síncronas. A junção desses pontos com o delicado momento vivido, pode também estar afetando diretamente o bem-estar dos residentes, uma vez que a maioria associa sentimentos ruins ao ensino remoto e se sentem mais tristes no momento atual em comparação ao período anterior à pandemia. Dessa forma, destacamos a necessidade de trabalhos que busquem conhecer as percepções dos diversos participantes do ensino remoto, bem como o impacto desse período no aprendizado e bem-estar de professores e alunos.

Palavras-chave: Ensino remoto; Educação digital; Formação de professores.

\footnotetext{
Abstract

The research sought to understand the perceptions of residents linked to the Pedagogical Residency Program (PRP) within the scope of the Federal Institute of Piauí (IFPI), with impact on the impacts of implementing the program in a remote setting. The research is characterized as basic, observational in nature and quali-quantitative approach. It is
} 
fully carried out online, using digital communication tools to contact residents. The formalization of participation occurs through the acceptance of a Free and Informed Consent Form (TCLE). For data collection, we used a semistructured questionnaire prepared through the Google Forms platform and sent to participants through the WhatsApp application. The answers to the answers show that the PRP-IFPI (2020-2022) is very important for the professional training of residents, and that despite the requirements imposed by remote learning, its implementation has been taking place in an adequate manner and providing diverse learning. Residents also point out as difficulties of basic education students in accessing digital technologies and the internet, as well as the frequent lack of interest and little participation in synchronous classes. The combination of these points with the delicate moment experienced may also be directly affecting the residents' well-being, as most of them associate feelings of ruins with remote education and feel sadder in the current moment compared to the period before the pandemic. Thus, we highlight the need for studies that seek to understand the perceptions of different participants in remote education, as well as the impact of this period on the teaching and well-being of teachers and students.

Keywords: Remote teaching; Digital education; Teacher training.

\section{Resumen}

La investigación buscó comprender las percepciones de los residentes vinculados al Programa de Residencia Pedagógica (PRP) en el ámbito del Instituto Federal de Piaú (IFPI), con impacto en los impactos de la implementación del programa en un entorno remoto. La investigación se caracteriza por ser básica, de naturaleza observacional y con un enfoque cuali-cuantitativo. Se realiza íntegramente en línea, utilizando herramientas de comunicación digital para contactar con los residentes. La formalización de la participación se produce mediante la aceptación de un Formulario de Consentimiento Libre e Informado (TCLE). Para la recolección de datos utilizamos un cuestionario semiestructurado elaborado a través de la plataforma Google Forms y enviado a los participantes a través de la aplicación WhatsApp. Las respuestas a las respuestas muestran que el PRP-IFPI (2020-2022) es muy importante para la formación profesional de los residentes, y que a pesar de las exigencias que impone el aprendizaje a distancia, su implementación se ha venido realizando de manera adecuada y brindando diversos aprendizajes. experiencias. Los vecinos también señalan las dificultades de los estudiantes de educación básica para acceder a las tecnologías digitales e internet, así como la frecuente falta de interés y poca participación en clases sincrónicas. La combinación de estos puntos con el delicado momento vivido también puede estar afectando directamente el bienestar de los vecinos, ya que la mayoría asocia sentimientos de ruinas con educación remota y se siente más triste en el momento actual en comparación con el período anterior a la pandemia. Así, destacamos la necesidad de estudios que busquen comprender las percepciones de los diferentes participantes en la educación a distancia, así como el impacto de este período en la docencia y el bienestar de docentes y estudiantes.

Palabras clave: Enseñanza remota; Educación digital; Formación de profesores.

\section{Introdução}

O Programa Residência Pedagógica (PRP) foi criado em 2018 pela Coordenação de Aperfeiçoamento de Pessoal de Nível Superior - CAPES, no uso das atribuições que lhe são conferidas pelo estatuto aprovado a partir do Decreto ${ }^{\circ} 8.977$, de 30 de janeiro de 2017 (Brasil, 2018). Esse programa integra a Política Nacional de Formação de Professores do Ministério da Educação, visando intensificar a formação prática nos cursos de licenciatura e promover a integração entre a Educação Básica e a Educação Superior (Brasil, 2019).

O público-alvo do PRP são estudantes de cursos de licenciatura ofertados por Instituições de Ensino Superior (IES).

Essa parceria objetiva inserir os licenciandos na rotina das escolas públicas da Educação Básica com o intuito de estimular e articular a teoria destes futuros profissionais com a prática docente, a partir de experiências vivenciadas. Além de oferecer bolsas aos discentes devidamente matriculados nas IES, o programa é constituído de alguns objetivos que estão em seu Art. $2^{\circ}$ da Portaria $n^{\text {o } 38, ~ d e ~} 28$ de fevereiro de 2018 (Brasil, 2018), sendo eles:

I. Aperfeiçoar a formação dos discentes dos cursos de licenciatura, por meio do desenvolvimento de projetos que fortaleçam o campo da prática e que conduzam o licenciando a exercitar de forma ativa a relação entre teoria e prática profissional docente, utilizando coleta de dados e diagnóstico sobre o ensino e a aprendizagem escolar, entre outras didáticas e metodologias; II. Induzir a reformulação do estágio supervisionado nos cursos de licenciatura, III. Fortalecer, ampliar e consolidar a relação entre a IES e a escola, promovendo sinergia entre a entidade que forma e aquelas que receberão os egressos das licenciaturas, além de estimular o protagonismo das redes de ensino na formação de professores; e IV. Promover a adequação dos currículos e das propostas pedagógicas dos cursos de formação inicial de professores da educação básica às orientações da Base Nacional Comum Curricular (Brasil, 
2018).

De acordo com Júnior e Cardoso (2020), o PRP, trata-se de uma política pública implantada com o objetivo de diminuir a escassez de docentes de diversas áreas de conhecimento como também ampliar a atuação de futuros professores no âmbito escolar. Para Leandro et al. (2020), a execução do programa proporciona melhorias na qualidade do ensino da rede pública, dado que vincula cursos de licenciatura da Educação Superior com os sistemas municipais e estaduais de ensino.

Em 06 janeiro de 2020, a CAPES por meio do edital 01/2020, tornou pública a seleção de até 250 IES públicas, privadas sem fins lucrativos e privadas com fins lucrativos (desde que tenham cursos de licenciatura com participantes que sejam bolsistas do Programa Universidade para Todos - PROUNI) interessadas em implementar projetos institucionais no âmbito do PRP, em conformidade com o processo no 23038.018770/2019-03 e outros dispositivos legais que o edital apresenta (Brasil, 2020).

O Instituto Federal do Piauí (IFPI) foi uma das instituições contempladas pelo referido edital, e suas atividades tiveram início em outubro de 2020 com previsão de término para março de 2022. O projeto PRP-IFPI conta com a participação de oito núcleos, distribuídos em sete municípios piauienses, sendo eles: Angical, Floriano, Parnaíba, Picos, Piripiri, Teresina e Uruçuí, contemplando discentes dos cursos de Licenciatura em Ciências Biológicas, Física, Informática, Matemática e Química.

A execução das atividades do PRP-IFPI (2020-2022) vem ocorrendo integralmente por meio do regime de aulas remotas e outras atividades desenvolvidas nas diversas escolas da Educação Básica participantes do programa, devido aos riscos relacionados à pandemia do novo Coronavírus. O home office em razão da suspensão das aulas nos espaços escolares físicos, transferiu as interações pedagógicas para os ambientes virtuais com as aulas remotas. Assim, o ensino remoto emergencial tornou-se uma forma de dar continuidade temporária aos estudos de milhares de estudantes, desde a Educação Infantil até o Ensino Superior.

Nessas circunstâncias, a execução das atividades do PRP-IFPI no cenário remoto exige um acompanhamento cuidadoso de todo o processo. Destacamos como fundamental o levantamento das percepções dos residentes relacionadas aos desafios impostos pelo isolamento social, impactos na aprendizagem e bem-estar dos participantes. Assim, esse artigo objetivou conhecer as percepções de residentes vinculados ao Programa Residência Pedagógica (PRP) no âmbito do Instituto Federal do Piauí (IFPI), com ênfase aos impactos de sua execução no cenário remoto.

\section{Metodologia}

Os frequentes desafios impostos pelo ensino remoto, apontados frequentemente em reuniões ou socializações no âmbito da RP-IFPI pelos seus diversos partícipes, motivaram a realização desse estudo. A referida pesquisa possui finalidade básica por objetivar adquirir conhecimentos novos que contribuam para o avanço da ciência, sem que haja uma aplicação prática prevista (Fontenelles et al., 2009) caracteriza-se como abordagem quali-quantitativa pois interpreta as informações quantitativas por meio de símbolos numéricos e os dados qualitativos mediante a observação, a interação participativa e a interpretação do discurso dos sujeitos (Knechtel, 2014). Também se classifica como exploratória quanto aos seus objetivos, e pesquisa de campo quanto aos seus procedimentos (Fontelles et al., 2009).

O público-alvo dessa pesquisa foi constituído por residentes do PRP-IFPI, aprovados pelo edital $\mathrm{n}^{\circ} 01$, de 14 de julho de 2020 /PROEN/ RP/ IFPI, distribuídos entre os oito Campus participantes do programa, sendo eles: Angical, Floriano, Parnaíba, Picos, Piripiri, Teresina Zona Sul, Teresina Central e Uruçuí, e os subprojetos são Biologia, Física, Informática, Matemática e Química. Dessa forma, a pesquisa contou com a participação de 129 residentes distribuídos nos Campus e subprojetos evidenciados anteriormente.

Os participantes foram apresentados aos objetivos da pesquisa e convidados a participar, sendo todo o diálogo 
realizado pela ferramenta de troca de mensagens WhatsApp, em respeito ao isolamento social em face da pandemia vigente. A formalização da participação ocorreu por meio do aceite a um Termo de Consentimento Livre e Esclarecido (TCLE), que dentre seus objetivos, assegura o anonimato dos participantes, permite a retirada dos dados da pesquisa a qualquer momento anterior à publicação, bem como assegura a divulgação científica dos dados coletados.

Após anuência dos participantes, estes responderam a um questionário semiestruturado composto por 15 questões que objetivaram conhecer a percepção dos residentes sobre o PRP ocorrido em período remoto, relatar o bem-estar dos residentes nesse período, bem como descrever desafios e aprendizados relacionados ao processo. Para construção do questionário, utilizou-se a ferramenta Google Forms e um link foi criado e enviado aos sujeitos da pesquisa, por meio do aplicativo de troca de mensagens WhatsApp.

Posterior à coleta de dados, realizou-se uma análise dos resultados em que para as perguntas objetivas foram descritas o número de respostas e porcentagens para cada questão. Foram também confeccionados gráficos que representavam as respostas dos participantes, utilizando-se para isso o programa Microsoft Excel (2013). Para a questão aberta, utilizou-se uma análise de conteúdo voltada à manipulação do texto para interpretação e inferência dos sentidos, fundamental para a categorização das respostas (Ferreira \& Loguecio, 2014). A representação literal da fala dos participantes ocorreu por meio da confecção de quadros.

\section{Resultados e Discussão}

Dentre os 129 participantes desta pesquisa, 78 pertencem ao gênero feminino, 49 ao gênero masculino, um participante se considerou não binário e um participante preferiu não declarar o gênero. A faixa etária variou de 19 a 39 anos, com predominância de indivíduos com idade entre 21 e 22 anos (42\%). A maioria dos residentes participantes da pesquisa são bolsistas (87\%) e estão agrupados em núcleos de Licenciatura em Ciências Biológicas (37\%), Matemática (33\%), Física (17\%), Química (9\%) e Informática (4\%).

Na primeira questão do formulário, indagou-se aos participantes sobre a importância do PRP para a sua formação profissional, sendo apresentadas as alternativas "muito importante", "pouco importante" e "sem importância". Nas respostas, todos os residentes apontaram a alternativa "muito importante". Esses dados se assemelham aos encontrados por Santos et al., (2020) que investigaram a percepção de residentes do Campus São Vicente do Sul a respeito do PRP para sua formação inicial, em que $98 \%$ dos participantes consideram o programa muito importante e imprescindível. Para Freitas, Freitas e Almeida (2020), o PRP favorece a troca mútua de saberes e aproxima o licenciando das reais demandas do ensino público, além de estimular a construção de uma formação de professores mais sólida que pode acompanhar as mudanças no âmbito educacional.

Na questão seguinte, perguntou-se aos participantes sobre a qualidade de execução do PRP que vem ocorrendo de forma exclusivamente remota. Nas respostas, 72 (55\%) residentes consideram bom, 32 (25\%) responderam excelentes, 24 (19\%) marcaram a opção regular e um participante (1\%) marcou a opção ruim. Um estudo realizado por Castro et al., (2021) na mesma instituição de ensino por nós pesquisada, apontou que 75\% dos preceptores participantes afirmaram ser boa a execução do PRP-IFPI (2020-2022), 21,4\% consideram excelente e apenas um apontou a alternativa regular, predominando nas respostas as alternativas bom e excelente nos dois estudos. Nenhum dos residentes apontaram a alternativa péssima, como observado na Figura 1. 
Figura 1: Representação gráfica das respostas dos participantes da pesquisa em relação a qualidade de execução do PRP-IFPI (2020-2022) ocorrido de forma remota.

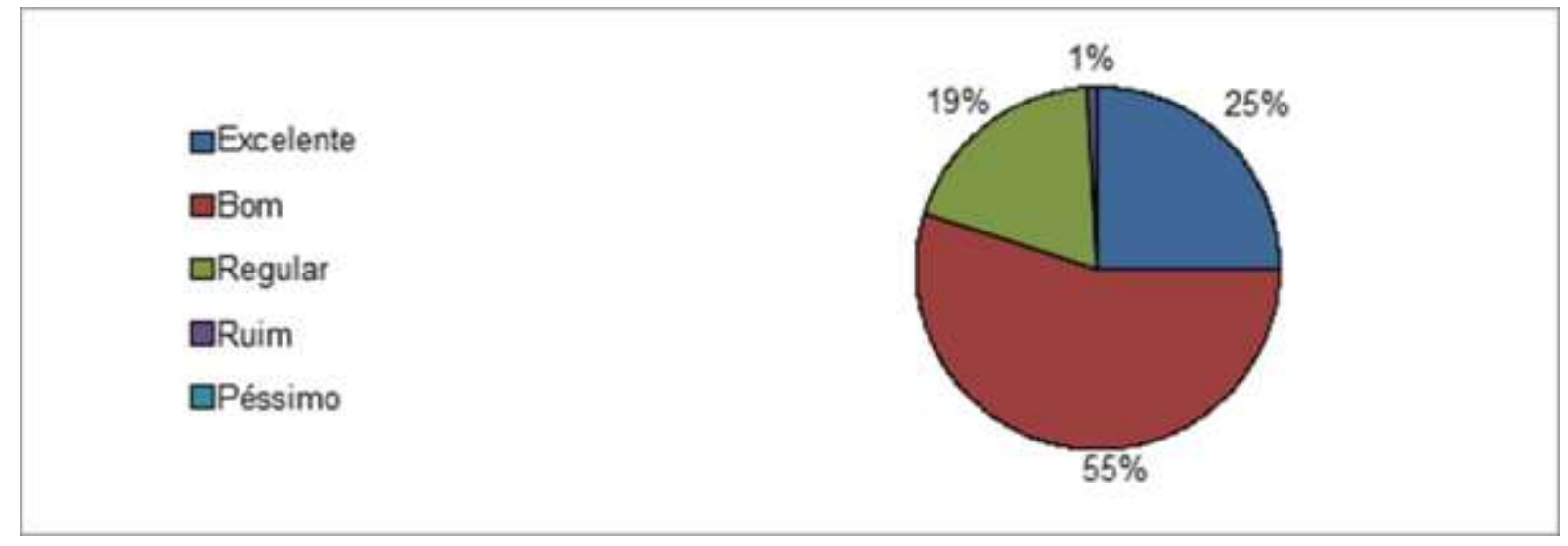

Fonte: Autores (2021).

$\mathrm{Na}$ terceira questão foi indagado aos residentes sobre sua preparação para a docência por meio do ensino remoto. Nas respostas, $82(63 \%)$ participantes afirmaram que só se sentem preparados para o ensino remoto agora, depois da pandemia, 37 (29\%) indivíduos ainda não se sentem preparados para o ensino remoto e 10 (8\%) residentes já se sentiam preparados para o ensino remoto antes da pandemia, como observado na Figura 2. Alinhado aos resultados por nós apresentados, Cardoso (2021) relatou que $60 \%$ dos professores de biologia da Universidade do Sul de Santa Catarina, afirmam se sentirem mais preparados para o ensino remoto após vivenciarem esse ensino no cenário pandêmico.

No mesmo direcionamento, Cigales e Souza (2021) ao realizarem um estudo com licenciandos da Universidade de Brasília que cursaram o estágio supervisionado de forma não presencial, constataram que 58\% dos estudantes se sentem parcialmente preparados para atuarem no ensino remoto. Acreditamos que os aprendizados adquiridos por meio do ensino remoto são essenciais na vida dos docentes - formados e em formação - uma vez que o compartilhamento de informações e aprimoramento de estratégias metodológicas foram estimuladas na pandemia, e serão exigidos no campo educacional, mesmo com a volta do ensino presencial.

Figura 2: Representação gráfica das respostas dos participantes da pesquisa em relação a sua preparação para o ensino remoto como docente em formação.

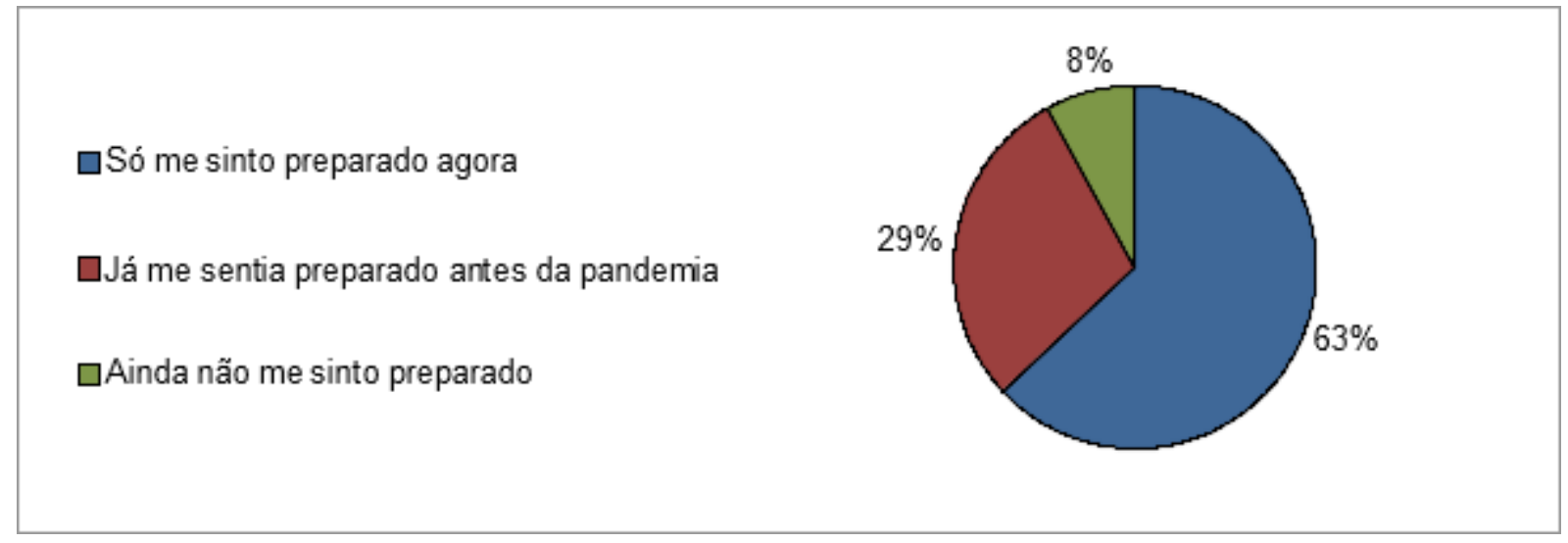

Fonte: Autores (2021).

A quarta questão teve cunho subjetivo, e solicitou aos discentes que apontassem suas percepções, desafios, 
sentimentos ou realizações em relação ao fazer docente no cenário pandêmico atual. As respostas de 19 (15\%) discentes demonstraram que esse momento contribuiu para o seu desenvolvimento pessoal; 17 (13\%) evidenciaram dificuldades no acesso à internet por parte dos discentes; 17 (13\%) apontaram a falta de interação com os estudantes como um fator que dificulta o ensino; 16 (12\%) demonstraram insegurança, medo ou frustração em relação ao ensino remoto; 15 (12\%) se sentiram despreparados para o ensino remoto; 13 (10\%) destacaram a importância de metodologias alternativas para o momento atual; 10 (8\%) relataram o desinteresse por parte dos discentes da escola-campo; 10 (8\%) não se sentiram simpatizantes ao ensino remoto; sete $(5 \%)$ relataram que adquiriram conhecimentos relacionados aos recursos didáticos tecnológicos, três (2\%) apontaram aspectos sociais percebidos, como o aumento da desigualdade educacional e, dois (2\%) disseram que inicialmente tiveram dificuldades, mas estas foram superadas. O Quadro 1 evidencia algumas das respostas dos discentes para as respectivas categorias acima apontadas.

Os dados obtidos na questão quatro estimulam reflexões na perspectiva de melhoria do ensino remoto e consequentemente o processo de ensino aprendizagem. Nobre et al. (2021) investigaram as motivações, tensões e expectativas de residentes vinculados a um curso de Licenciatura em Matemática da Universidade Federal de Pelotas, em relação à prática docente durante o ensino remoto. Seus dados de forma semelhante aos nossos, evidenciaram a falta de acesso à internet, falta de interação e feedback por parte dos estudantes, pouca familiaridade ou domínio das ferramentas digitais, como principais dificuldades na condução do ensino remoto pelos residentes. $\mathrm{O}$ autor aponta ainda que tais fatores geraram sentimentos de medo e insegurança durante a regência, como também proporcionou aprendizados para alguns residentes.

Outra dificuldade que os residentes relataram em nosso estudo, diz respeito a efetividade da aprendizagem por parte dos alunos, já que estar conectado não significa que estão atentos às aulas e realizando suas atividades escolares (Dias et al., 2020; Souza \& Miranda, 2020). Somado a essas dificuldades, estamos enfrentando uma crise sanitária mundial, falta de acesso a uma alimentação adequada, ataques aos direitos trabalhistas, sucateamento do Sistema Único de Saúde e diversos outros fatores que dificultam ainda mais o acesso educacional, principalmente aos mais vulneráveis (Faria, 2020; Cardoso \& Mendonça, 2020; Magalhães, 2021).

Quadro 1. Algumas Respostas dos residentes em relação às suas percepções, desafios, sentimentos ou realizações em relação ao fazer docente no cenário pandêmico atual.

\begin{tabular}{|c|c|l|}
\hline Categorias & Frequência (\%) & \multicolumn{1}{c|}{ Transcrição literal das falas } \\
\hline $\begin{array}{c}\text { Desenvolvimento } \\
\text { profissional }\end{array}$ & $15 \%$ & $\begin{array}{l}\text { Aluna (o) 30: "É muito diferente e desafiador do que estávamos acostumados a } \\
\text { vivenciar, porém trouxe muitos aprendizados e experiências positivas." }\end{array}$ \\
\hline $\begin{array}{c}\text { Dificuldade ou falta de } \\
\text { acesso à internet pelos } \\
\text { discentes }\end{array}$ & $13 \%$ & $\begin{array}{l}\text { Aluna (o) 125: "É um momento de aprendizagem, reflexão diante do momento } \\
\text { atípico que estamos vivendo. Um dos grandes desafios, é fazer com que a } \\
\text { mensagem chegue a todos, já que nem todos têm acesso a internet." }\end{array}$ \\
\hline $\begin{array}{c}\text { Falta de interação com os } \\
\text { estudantes }\end{array}$ & $13 \%$ & $\begin{array}{l}\text { Aluna (o) 20: "O maior desafio que vejo é o contato com os alunos para que se } \\
\text { tenha um diagnóstico maior se eles de fato estão aprendendo, como muitos não } \\
\text { possuem acesso ou acesso limitado essa comunicação fica fragilizada, bem } \\
\text { como também a aprendizagem." }\end{array}$ \\
$\begin{array}{c}\text { Sentimento de } \\
\text { insegurança, medo ou } \\
\text { frustração }\end{array}$ & $12 \%$ & $\begin{array}{l}\text { Aluna (o) 26: "Usar o ensino remoto não é ruim, mas é muito limitante e, por } \\
\text { ser uma situação passageira é meio frustrante, no meu caso, por não poder ter } \\
\text { a oportunidade de, durante a graduação, atuar de forma presencial e entender } \\
\text { a dinâmica da escola, o que me deixa apreensiva e insegura em relação à volta } \\
\text { das aulas presenciais e minha inexperiência nesse quesito. Mas acredito que } \\
\text { essa experiência remota também é valiosa e está ajudando em relação ao uso }\end{array}$ \\
\hline
\end{tabular}


Research, Society and Development, v. 10, n. 13, e69101320707, 2021

(CC BY 4.0) | ISSN 2525-3409 | DOI: http://dx.doi.org/10.33448/rsd-v10i13.20707

\begin{tabular}{|c|c|c|}
\hline & & das tecnologias para fins didáticos." \\
\hline $\begin{array}{l}\text { Despreparo para o ensino } \\
\text { remoto }\end{array}$ & $12 \%$ & $\begin{array}{l}\text { Aluna (o) 44: O ensino a distância não é a mesma coisa do ensino presencial e } \\
\text { um dos meus maiores medos é não estar preparada para o ensino presencial. }\end{array}$ \\
\hline Metodologias alternativas & $10 \%$ & $\begin{array}{l}\text { Aluna (o) 62: “O desafio maior foi trazer os assuntos de forma dinâmica nas } \\
\text { aulas remotas, buscar o interesse dos alunos pela disciplina de forma que eles } \\
\text { não se sentissem saturados pela forma de ensino." }\end{array}$ \\
\hline $\begin{array}{l}\text { Desinteresse dos } \\
\text { estudantes }\end{array}$ & $8 \%$ & $\begin{array}{l}\text { Aluna (o) 89: "Dar aulas a distância é até que possível, porém não se obtém } \\
\text { um bom retorno dos alunos. Os mesmos não focam na aula e poucos fazem as } \\
\text { atividades propostas." }\end{array}$ \\
\hline $\begin{array}{l}\text { Não simpatizantes ao } \\
\text { ensino remoto }\end{array}$ & $8 \%$ & $\begin{array}{l}\text { Aluna (o) } 70 \text { "Expectativa que esse momento acabe logo e nós Professores e } \\
\text { alunos possamos voltar a sala de aula". }\end{array}$ \\
\hline $\begin{array}{l}\text { Agregou conhecimentos } \\
\text { tecnológicos }\end{array}$ & $5 \%$ & $\begin{array}{l}\text { Aluna (o) 101: “A RP alcançou minhas expectativas, e apesar de ser de forma } \\
\text { remota fui capaz de desenvolver e experimentar novas vivências por meio da } \\
\text { tecnologia." }\end{array}$ \\
\hline Aspectos sociais & $2 \%$ & $\begin{array}{l}\text { Aluna (o) 14: "A pandemia gerou muitas consequências negativas para a } \\
\text { sociedade como um todo. No âmbito educacional, as dificuldades que já eram } \\
\text { fortemente expressas na modalidade presencial, tomaram dimensões ainda } \\
\text { maiores na modalidade remota, seja devido às vulnerabilidades sociais, } \\
\text { psicológicas elou emocionais. Isso torna tanto o processo de ensino quanto o } \\
\text { de aprendizagem mais complexo. Contudo, também houve muito } \\
\text { desenvolvimento de habilidades a partir da utilização de novos recursos e, } \\
\text { obviamente, contribuições para a formação docente. }\end{array}$ \\
\hline Dificuldades superadas & $2 \%$ & $\begin{array}{l}\text { Aluna (o) 123: "Foi difícil no início, mas com o tempo foi ficando menos } \\
\text { complicado." }\end{array}$ \\
\hline
\end{tabular}

Fonte: Autores (2021).

Na pergunta cinco, os participantes foram questionados sobre a principal motivação em participar do PRP. Um total de 82 (64\%) residentes participam por causa das experiências pedagógicas que o programa proporciona, 17 (13\%) responderam agregar ao currículo, $14(11 \%)$ participam para realizarem o aproveitamento do estágio supervisionado obrigatório, $13(10 \%)$ estão no programa devido a remuneração e três $(2 \%)$ participaram pela curiosidade em relação às vivências que programa proporciona, como observa-se na Figura 3.

Em consonância aos nossos resultados, relatamos o estudo de Santos et al., (2020) que realizaram um trabalho com residentes do PRP e bolsistas do PIBID, vinculados a Universidade Federal do Acre. Em seus resultados os autores apontaram que 35\% dos pesquisados aceitaram participar dos programas para experimentar a docência e aprimorar seus conhecimentos, enquanto $25 \%$ relataram que sua maior motivação está relacionada à remuneração proporcionada pela bolsa. Nesse sentido, reafirmamos a importância do PRP e demais programas de estímulo à docência, uma vez que fortalecem a relação entre Educação Básica e Superior, ao passo que proporciona experiências pedagógicas e remuneração para a maioria dos participantes, valor esse que estimula a permanência do estudante no curso. 
Figura 3: Representação gráfica das respostas dos participantes da pesquisa em relação ao motivo de sua participação na Residência Pedagógica.

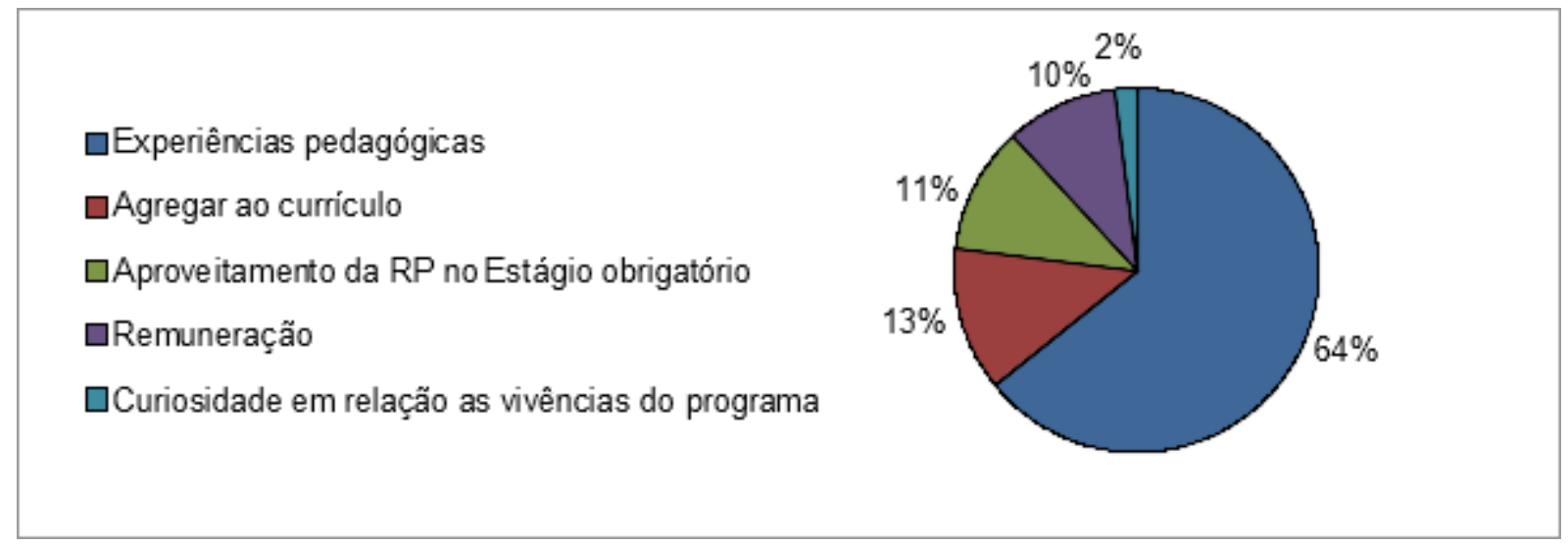

Fonte: Autores (2021).

$\mathrm{Na}$ sexta questão, indagou-se quanto ao grau de dificuldade dos residentes em relação ao uso dos recursos tecnológicos necessários para o ensino remoto. Ao todo, 85 (66\%) participantes sentem poucas dificuldades, 34 (26\%) não sentem dificuldades e $10(8 \%)$ afirmam sentir muita dificuldade. Proporções muito similares a essas são encontradas no estudo de Perin, Silva e Valetim (2020). Em sua pesquisa, os autores buscaram conhecer a opinião de docentes em relação ao ensino remoto, e nas respostas, mais de $60 \%$ dos entrevistados afirmaram que não tinham muitas dificuldades em utilizar recursos tecnológicos, e somente $7 \%$ afirmaram ter grande dificuldades em manuseá-los.

Indagou-se aos residentes na questão seguinte sobre quais plataformas digitais eram mais utilizadas por eles para o ensino remoto. Nas respostas, 125 residentes (97\%) usam o aplicativo WhatsApp, 120 (93\%) utilizam a ferramenta Google Meet, 99 (77\%) usam a plataforma Youtube, 97 (75\%) utilizam o aplicativo Google Forms, 74 participantes (57\%) utilizam email, 11 (8\%) utilizam o Zoom Meeting e três (2\%) participantes utilizam o Moodle, como observado na Figura 4. Có, Amorim e Finardi (2020) obtiveram resultados distintos ao realizarem um estudo na Universidade Federal do Espírito Santo com os professores da educação básica e superior. Nas respostas, a ferramenta mais utilizada foi o Zoom Meeting (56\%) e somente $1,6 \%$ dos participantes usavam o WhatsApp para a finalidade educacional.

Figura 4: Representação gráfica das respostas dos participantes da pesquisa em relação às plataformas digitais por eles utilizadas para o ensino remoto.

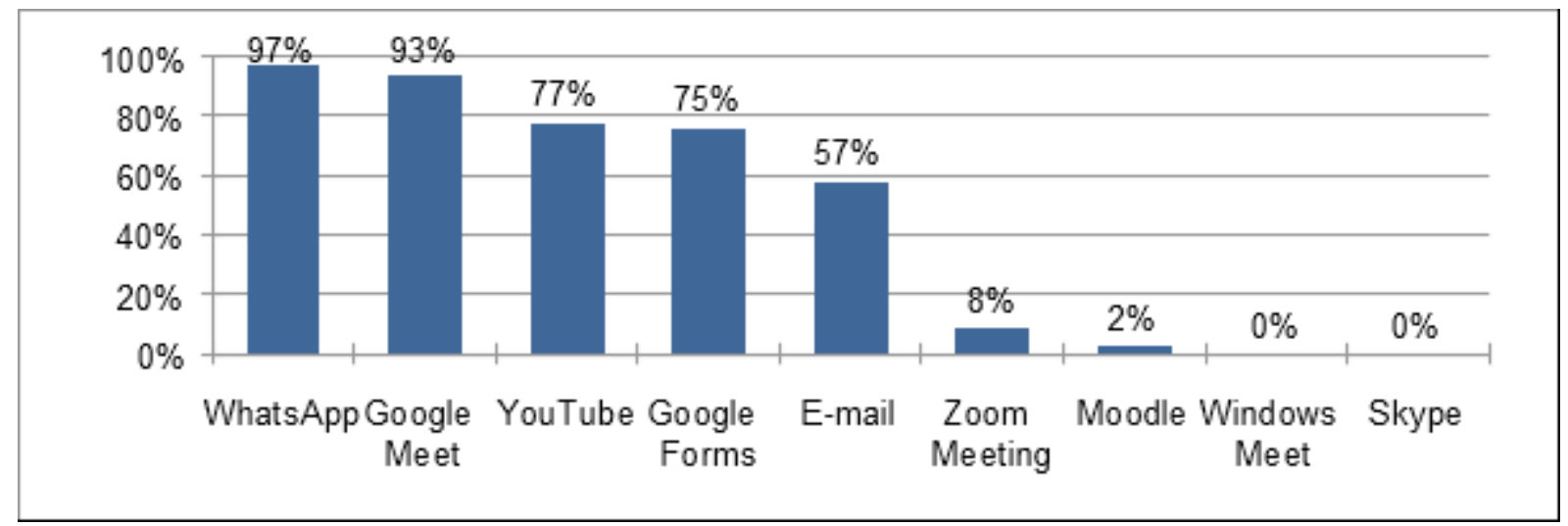

Fonte: Autor (2021). 
Mediante o contexto pandêmico vivenciado e a imposição do ensino remoto nas escolas, buscamos conhecer também a relação desses fatores com o bem-estar dos residentes. A questão oito pediu aos residentes que refletissem sobre sua felicidade antes da pandemia e no atual cenário. Nas respostas, 88 (68\%) participantes se sentiam mais felizes antes da pandemia, 31 (24\%) não perceberam mudanças no seu nível de felicidade e 10 (8\%) afirmaram que se sentem mais felizes atualmente do que antes da pandemia, como observado na Figura 5. Este resultado pode estar relacionado com as alterações emocionais dos estudantes frente às mudanças abruptas que ocorreram no cotidiano das pessoas após o surgimento da pandemia, afetando o seu grau de felicidade ou satisfação, uma vez que os estudantes tiveram que lidar com a ruptura da rotina pessoal e com incertezas relacionadas a continuidade do percurso acadêmico (Silva \& Rosa, 2021).

Figura 5: Representação gráfica das respostas dos participantes da pesquisa em relação a sua felicidade antes da pandemia em comparação ao período atual.

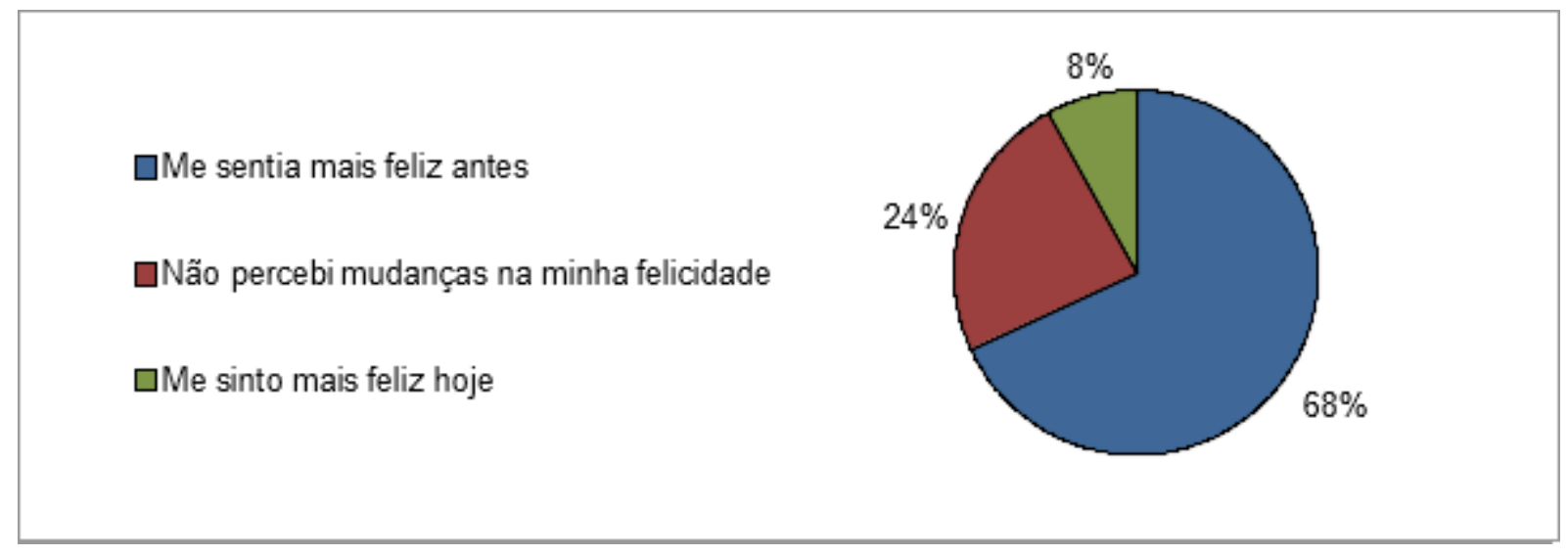

Fonte: Autores (2021).

$\mathrm{Na}$ nona questão, pediu-se aos residentes que escolhessem um sentimento que melhor lhes representasse o ensino remoto imposto pela pandemia. Nas respostas, observou-se que 45 (35\%) participantes marcaram ansiedade, 32 (25\%) apontaram insatisfação, 17 (13\%) relataram satisfação, 16 (12\%) apontaram estresse, 12 (9\%) relataram angústia, cinco (4\%) evidenciaram tristeza e dois $(2 \%)$ alegria. A representação gráfica das respostas pode ser observada na Figura 6. Esse dado pode ser comparado ao estudo realizado por Vieira et al. (2020), que visou avaliar a percepção de estudantes universitários sobre o efeito do isolamento social, da mudança para o ensino remoto e a alteração na satisfação com a vida. Os autores constataram que a maioria dos estudantes apresentou alterações de humor e sentimentos de angústia e ansiedade. 
Figura 6: Representação gráfica das respostas dos participantes da pesquisa em relação ao seu principal sentimento para o ensino remoto.

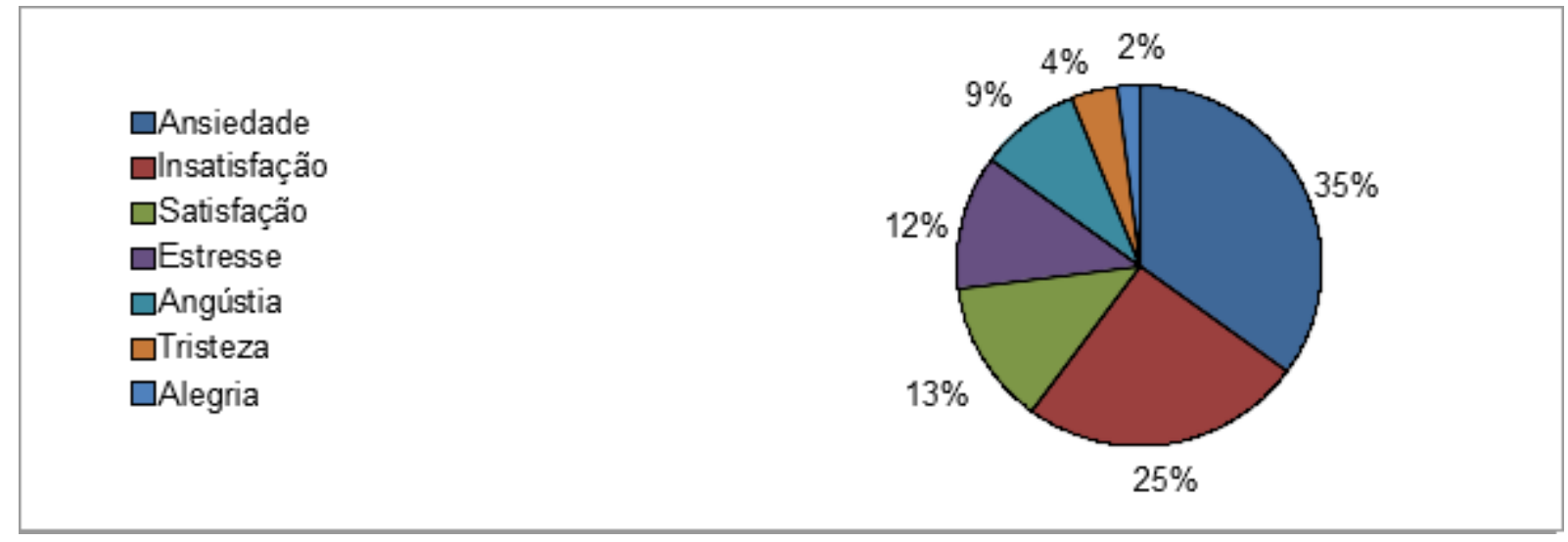

Fonte: Autores (2021).

Na questão 10, os discentes foram perguntados sobre seu nível de estresse relacionado ao trabalho como docente em formação por meio do ensino remoto. Nas respostas, 51 residentes $(39 \%)$ consideram pouco estressante, $42(33 \%)$ consideram muito estressante, $15(12 \%)$ declaram que não causa estresse, $13(10 \%)$ dizem que é tão estressante quanto de forma presencial e oito participantes $(6 \%)$ declaram que a forma presencial causava mais estresse do que a forma remota, como observado na Figura 7. Pedrolo et al. (2020) investigaram o impacto da pandemia no estresse de docentes de uma Instituição Federal, constataram que a maioria dos participantes se sentem estressados em fase de resistência (segundo estágio do estresse). Já Barbosa et al. (2020), pesquisaram o nível de estresse e atividade física dos docentes de um Instituto Federal da região Norte do Brasil, constataram um alto grau de estresse, a carga horária elevada e a sobrecarga de trabalho foram apontadas como possíveis fatores causadores.

Figura 7: Representação gráfica das respostas dos participantes sobre o estresse causado na ministração de aulas ao compararse o ensino remoto ao presencial.

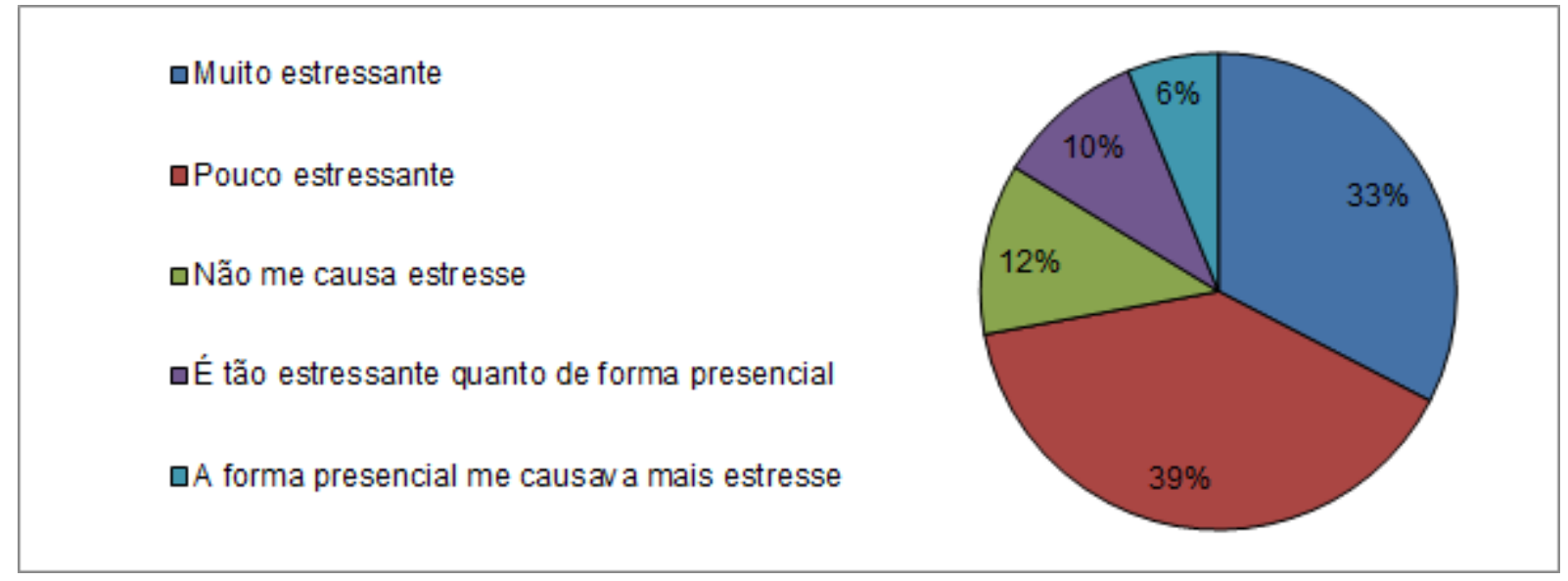

Fonte: Autores (2021).

Na questão 11, os residentes foram questionados sobre a principal dificuldade em relação ao seu papel docente no ensino remoto. Nas respostas, observou-se que 46 (36\%) residentes apontaram a falta de acesso dos estudantes à internet, 37 (29\%) consideram a falta de interesse dos alunos, 31 (24\%) destacam a falta de recursos digitais dos estudantes, sete (5\%) relatam a pouca estrutura oferecida aos residentes, seis (4\%) apontam não ter domínio relacionado às tecnologias digitais, um 
participante (1\%) direciona sua dificuldade à falta de empatia dos funcionários da escola campo que atua, e um (1\%) afirma que é a junção de todas as alternativas, como demonstrado na Figura 8. Nessa direção, Souza e Miranda (2020), ao realizarem um trabalho sobre os desafios da implementação do ensino remoto, também evidenciaram a falta de acesso à internet e recursos tecnológicos por parte dos discentes como uma das principais dificuldades para esta forma de ensino.

Figura 8: Representação gráfica das respostas dos participantes da pesquisa em relação à principal dificuldade para a sua prática docente no ensino remoto.

$\square$ Falta de acesso dos alunos à internet

$\square$ Desinteresse dos alunos

$\square$ Falta de recursos digitais aos alunos

$\square$ Pouca estrutura oferecida ao residente

$\square$ Falta de domínio das tecnologias digitais

$\square$ Falta de empatia dos servidores da escola campo

$\square$ A junção de todas as alternativas

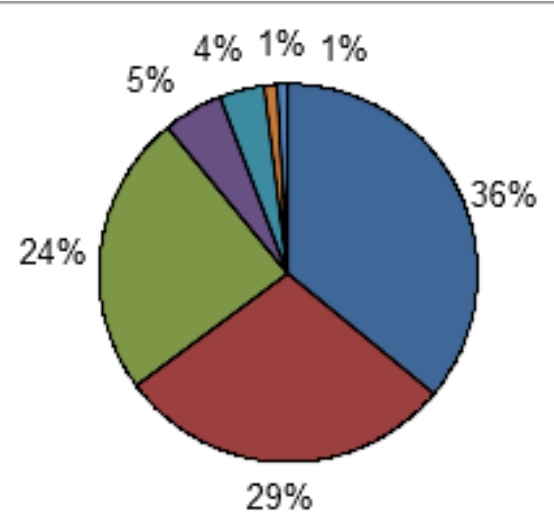

Fonte: Autores (2021).

Na questão 12, perguntou-se ao residente sobre sua demanda de trabalho na comparação entre o momento anterior à pandemia e ao cenário atual. Nas respostas, 88 (67\%) participantes afirmam que sua demanda de trabalho está maior agora, 27 (21\%) participantes apontam que não há diferença e 16 (12\%) participantes relatam uma menor demanda de trabalho no cenário atual, como observado na Figura 9. Praça e Oliveira (2020) ao investigarem os impactos causados pela pandemia da COVID-19 na qualidade de vida no trabalho dos docentes do ensino superior, observou-se que 97\% dos docentes apontam que o método de ensino online possui mais tarefas que o presencial. Ladeira, Prado e Insfran (2020) em seu estudo com professores no Noroeste Fluminense, evidenciaram um aumento da carga horária de 20 horas semanais em média com a implementação do ensino remoto.

Figura 9: Representação gráfica das respostas dos participantes da pesquisa em relação a sua demanda de trabalho.

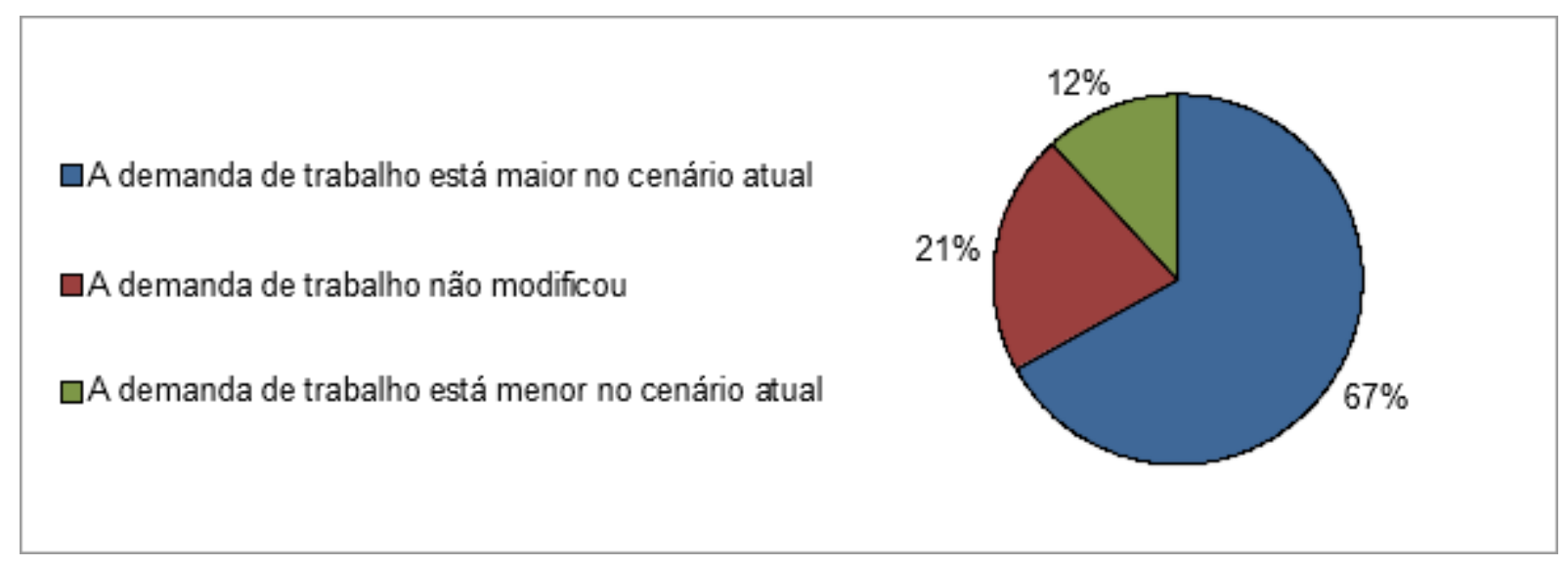

Fonte: Autores (2021). 
Na questão 13, os residentes foram indagados sobre os aprendizados construídos por meio de sua participação no PRP que vem ocorrendo integralmente em período remoto. Nas respostas, observou-se que 62 (48\%) participantes aprenderam mais do que o esperado, 57 (44\%) participantes aprenderam como esperado e $10(8 \%)$ participantes aprenderam menos do que o esperado, como observado na Figura 10. Esse dado aponta para a importância de continuidade do programa, uma vez que a maioria dos estudantes apresentou resultados de aprendizagem que são relevantes para a qualificação profissional. Nessa direção, Da Silva et al. (2019) ao analisarem o progresso, enquanto docentes em formação, de residentes de licenciatura em Ciências Biológicas da Paraíba, avaliaram que de uma forma homogênea, de modo geral os estudantes tiveram um avanço considerável ao longo de suas atividades, tornando-os capazes de fortalecer suas vivências pessoais enquanto graduandos.

Figura 10: Representação gráfica das respostas dos participantes da pesquisa em relação aos seus aprendizados construídos por meio de sua participação na Residência Pedagógica.

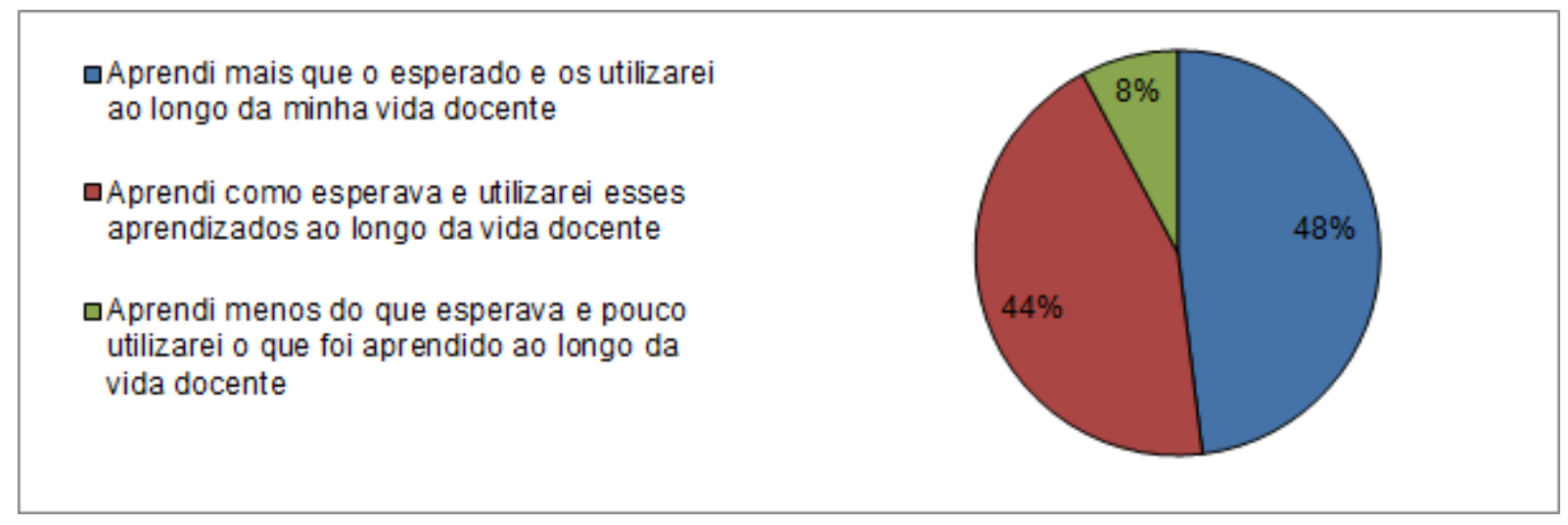

Fonte: Autores (2021).

$\mathrm{Na}$ pergunta 14, foi questionado se os residentes se sentem mais preparados para aulas presenciais frente aos aprendizados obtidos neste período de pandemia. Nas respostas, 96 (74\%) participantes afirmaram que sim, e 33 (26\%) responderam que não. Os dados da pesquisa de Motta (2021) vão de encontro aos nossos, uma vez que ao realizar um questionário para licenciandos em Geografia, evidenciou que a maioria dos participantes se sentem mais preparados para as aulas presenciais depois das experiências proporcionadas pelo ensino remoto. Paulo Freire na obra Pedagogia da Autonomia, evidencia que ensinar exige compreensão da realidade, e aponta que as experiências educativas adquiridas irão tornar o professor seguro de sua prática docente. $\mathrm{O}$ docente deve conhecer todas as diferentes dimensões que caracterizam essencialmente sua prática e vivenciar a capacidade de aprender a transformar sua realidade (Freire, 1998).

$\mathrm{Na}$ questão seguinte, os residentes foram indagados se a partir das experiências vivenciadas no PRP pretendem realizar mudanças metodológicas em suas aulas presenciais em um período posterior ao da pandemia. Nas respostas, 126 (98\%) residentes responderam que sim e, três (2\%) responderam que não. Esses resultados vão de encontro aos dados da pesquisa de Rondini, Pedro e Duarte (2020). Ao realizarem um estudo com professores de 50 municípios de São Paulo, identificaram que 119 (70\%) participantes irão manter os recursos tecnológicos utilizados na pandemia para o ensino presencial. Destacamos assim, que apesar dos desafios impostos pelo ensino remoto, os aprendizados são valiosos e marcaram de alguma forma a vida profissional de todos os envolvidos nesse processo educacional.

\section{Considerações Finais}

Os resultados aqui apresentados demonstram que todos os esforços realizados para a efetiva implementação do PRPIFPI (2020-2022) foram fundamentais e têm proporcionado reflexões, experiências e aprendizados diversos aos residentes 
participantes. Destacamos também que a insuficiente preparação dos atores educacionais para o ensino remoto, bem como carências nas estruturas escolares, intensificou os desafios dos residentes, e que estes mostraram dinamismo e capacidade rápida de adaptação para transpor diversas barreiras.

Apontamos, no entanto, que alguns obstáculos foram intransponíveis pelos residentes, apesar de todos os esforços, como por exemplo as dificuldades dos estudantes da educação básica no acesso às tecnologias digitais e internet, ou frequente desinteresse e pouca participação dos discentes nas aulas síncronas. Tais resultados se somam a outros trabalhos anteriormente publicados, e demonstram defasagem educacional e aumento da desigualdade social, que reflete diretamente na falta de acesso de muitos estudantes as tecnologias necessárias ao adequado funcionamento do ensino remoto.

Por fim, ressaltamos que a junção das dificuldades anteriormente relatadas com o delicado momento vivido, podem estar afetando diretamente o bem-estar dos residentes, uma vez que a maioria associa sentimentos ruins ao ensino remoto e se sentem mais tristes no momento atual em comparação ao período anterior à pandemia. Dessa forma, asseguramos a necessidade da realização de outros trabalhos que busquem conhecer o impacto desse período vivido a todos os atores escolares, bem como a realização de ações que estimulem a saúde física e mental de professores e docentes em formação.

\section{Agradecimentos}

Agradecemos à Coordenação de Aperfeiçoamento de Pessoal de Nível Superior (CAPES) pelo suporte ao Programa Residência Pedagógica, e pelo estímulo a integração entre Educação Básica e Superior. Agradecemos também ao Instituto Federal do Piauí (IFPI) em nome do professor Valtércio de Almeida Carvalho pelo apoio irrestrito, e por proporcionar as condições necessárias ao bom desenvolvimento do programa. Por fim, agradecemos a todos os Residentes que disponibilizaram seu valioso tempo para participação dessa pesquisa.

\section{Referências}

Barbosa, T. C., Silva, A. P., Peixoto, F. R., Quaresma, F. R. P., \& Maciel, E. S. (2020). Estresse percebido e nível de atividade física em docentes de um Instituto Federal. Saúde em Revista, 20(52), 47-56.

Brasil. (2018). Portaria $n^{o} 38$, de 28 de fevereiro de 2018. Institui o Programa Residência Pedagógica. https://www.gov.br/capes/pt-br/centrais-deconteudo/28022018-portaria-n-38-institui-rp-pdf.

Brasil. (2019). Portaria $n^{\circ}$ 259, de 17 dezembro de 2019. Dispõe sobre o regulamento do Programa de Residência Pedagógica e do Programa Institucional de Bolsa de Iniciação à Docência (PIBID). https://www.in.gov.br/en/web/dou/-/portaria-n-259-de-17-dezembro-de-2019-234332362

Brasil. (2020a). Edital $n^{o}$ 01/2020. A Coordenação de Aperfeiçoamento de Pessoal de Nível Superior - CAPES, instituída como fundação pública pela Lei nº. 8.405, de 09 de janeiro de 1992, por meio de sua Diretoria de Formação de Professores da Educação Básica (DEB), torna pública a seleção de Instituições de Ensino Superior (IES) interessadas em implementar projetos institucionais no âmbito do Programa Residência Pedagógica (RP), conforme processo $\mathrm{n}^{\circ}$ 23038.018770/2019-03. https://www.gov.br/capes/pt-br/centrais-de-conteudo/06012020-edital-1-2020-residencia-pedagogica-pdf

Brasil. (2020b). Edital no 01 de 14 de julho de 2020/ PROEN/RP/IFPI. Seleção de alunos para o Programa Institucional de Bolsa de Residência Pedagógica do IFPI. https://www.ifpi.edu.br/noticias/ifpi-divulga-editais-para-pibid-e-residencia-pedagogica-1/discentes.pdf

Cardoso, J. (2021). A percepção dos professores de ciências e biologia da rede pública estadual a respeito do ensino remoto emergencial ocasionado pela COVID-19 (Trabalho de Conclusão de Curso). Universidade do Sul de Santa Catarina, Tubarão, SC, Brasil.

Cardoso, N. S., \& Mendonça, S. G. L. (2020). FORPIBID-RP e a politização como enfrentamento ao ensino remoto. Revista Formação em Movimento, 2(4), 647-654. https://doi.org/10.38117/2675-181X.formov2020.v2i2n4.647-654

Castro, I. F. A., Cipriano, T. H. A. S., Costa, F. C., Castro, K. S., Costa, V. S., Pires, G. R., et al. (2021). Pedagogical Residency and remote teaching: challenges and perspectives in the view of basic education teachers participating in the program. Research, Society and Development, $10(11)$, e75101119359. http://dx.doi.org/10.33448/rsd-v10i11.19359

Cigales, M. P., \& de Souza, R. D. (2021). O Estágio Curricular Supervisionado em tempos de pandemia: um debate em construção. Latitude, 14(1), 286-310.

Có, E. P., Amorim, G. B., \& Finardi, K. R. (2020). Ensino de línguas em tempos de pandemia: experiências com tecnologias em ambientes virtuais. Revista Docência e Cibercultura, 4(3), 112-140. https://doi.org/10.12957/redoc.2020.53173

Da Silva, F. V. C., dos Santos, A. L. C., dos Santos, L. G. T., \& Feitosa, A. A. F. M. A. (2019, outubro). Residência Pedagógica de Biologia: percepção dos residentes sobre as contribuições do programa em sua formação docente, João Pessoa-Pb, Brasil. Anais do VI Congresso Nacional de Educação, Fortaleza, Ceará, Brasil, 6. https://editorarealize.com.br/editora/anais/conedu/2019/TRABALHO_EV127_MD4_SA1_ID4109_16082019095622.pdf. 
Dias, G. N., Volgado, G. E. R., Barreto, W. D. L., Silva-Junior W. L., Barbosa, E. S., Rodrigues, A. E., Silva-Junior, A. F., \& Costa, C. A. C. (2020). Retorno às aulas presenciais no sistema educacional do estado do Pará-Brasil: Obstáculos e desafios durante a epidemia de Covid-19 (Sars-Cov-2). Brazilian Journal of Development, 6(6), 37906-24. https://doi.org/10.34117/bjdv6n6-358

Dos Santos, A. L. C., Feitosa, A. A. F. M. A. da Silva, F. V. C., \& dos Santos, L. G. T. (2020). Residência Pedagógica de Biologia: percepção dos residentes sobre as contribuições do programa em sua formação docente. In S. A. S. Monteiro (Org.), As Metas Preconizadas para a Educação e a Pesquisa Integrada às Práticas Atuais (p. 248-259). Ponta Grossa - PR: Atena.

Faria, L. G. (2020). Covid-19, ensino remoto emergencial e a democratização do acesso à educação no Brasil. https://repositorio.uniceub.br/jspui/bitstream/prefix/14320/1/Lucas\%20Gomes\%20Faria.pdf.

Ferreira, M., \& Loguecio, R. Q. (2014). A análise de conteúdo como estratégia de pesquisa interpretativa em educação em ciências. Revista de Educação, Linguagem e Literatura, 6(2), 33-49. https://lume.ufrgs.br/handle/10183/142567

Fontelles, M. J., Simões, M. G., Farias, S. H., \& Fontelles, R. G. S. (2009). Scientific research methodology: Guidelines for elaboration of a research protocol. Revista paraense de medicina, 23(3), 1-8.

Freire, P. (1996). Pedagogia da autonomia: saberes necessários à prática educativa. São Paulo: Paz e Terra. https://nepegeo.paginas.ufsc.br/files/2018/11/Pedagogia-da-Autonomia-Paulo-Freire.pdf

Freitas, M. C. de., Freitas, B. M. de., \& Almeida, D. M. (2020). Residência pedagógica e sua contribuição na formação docente. Ensino em Perspectivas, 1(2), $1-12$.

Júnior, L. P. R., \& Cardoso, M. G. R. (2020). O Programa Residência Pedagógica e a aproximação com a docência em biologia: vivências, desafios e possibilidades. Revista da Faculdade de Educação, 34(2), 101-120.

Knechtel, M. R. (2014). Metodologia da pesquisa em educação: uma abordagem teórico-prática dialogada. Intersaberes 11(2).

Ladeira, T. A., Prado, P., \& Insfran, F. (2020). Adoecimento e medicalização de professores do noroeste fluminense antes e durante a pandemia covid-19. Pandemia e suas interfaces no ensino. São Carlos: Pedro \& João Editores, 1-380. https://pedroejoaoeditores.com/wpcontent/uploads/2021/01/ebookPandemia.pdf\#page=184.pdf.

Leandro, B. B., Et. al. (2020). Transformação docente: programa residência pedagógica na formação inicial de professores. Série Educar - Formação Docente, 52-58.

Magalhães, R. C. D. S. (2021). Pandemia de covid-19, ensino remoto e a potencialização das desigualdades educacionais. História, Ciências, Saúde. https://doi.org/10.1590/S0104-59702021005000012.

Motta, A. A. (2021). Os impactos do ensino remoto emergencial e uso das tecnologias digitais, como ferramenta pedagógica na formação de novos professores de geografia: experiências do estágio no ensino médio em tempos de pandemia. (Trabalho de Conclusão de Curso). Universidade Federal da Fronteira Sul, Erechim, Rio Grande do Sul, Brasil.

Nobre, O. C. de., Borges, L. M. F., Beloni, A. B. B., \& da Conceição, D. L. (2021). Residência Pedagógica em tempos de pandemia: motivações, tensões e expectativas dos bolsistas para o início das práticas no ensino remoto. XIV/EGEM - Encontro Gaúcho de Educação Matemática/UFPel, 1-10.

Pedrolo, E., de Lima Santana, L., Ziesemer, N. D. B. S., de Carvalho, T. P. T. H., \& Haeffner, R. (2021). The impact of the COVID-19 pandemic on the quality of life and stress of teachers in a federal institution. Research, Society and Development, 10 (4), e 43110414298-e43110414298. https://doi.org/10.33448/rsd-v10i4.14298

Perin, A. P. J., Silva, D. E., \& Valentim, N. M. (2021). Experiência de docentes do Ensino Médio em Conduzir Atividades Remotas Durante o Distanciamento Social: uma Análise Baseada no Contexto da Educação 4.0. Anais do Computer on the Beach, 141-148.

Praça, L. A., \& Oliveira, V. M. (2020). Qualidade de vida no trabalho em tempos de pandemia de COVID-19: os desafios e oportunidades dos docentes do ensino superior. Gestão-Revista Científica, 2(2), 1-27.

Rondini, C. A., Pedro, K. M., \& Duarte, C. D. (2020). Pandemia do Covid-19 e o ensino remoto emergencial: Mudanças na práxis docente. Interfaces Científicas-Educação, 10(1), 41-57. https://doi.org/10.17564/2316-3828.2020v10n1p41-57

Santos, B. M., do Nascimento, S. L., Melo Junior, E. B., \& Silva, M. C. (2020). Reflexões quanto às motivações da licenciatura em física da UFAC para participar dos programas: Pibid e Residência Pedagógico. Formação@docente, 12(1), 187-202.

Santos, E. B., Martins, M., Ramos, M. R. S., Neto, H., \& Paniz, C. M. (2020). A importância do Programa de Residência Pedagógica na formação de professores no Instituto Federal Farroupilha, Campus São Vicente do Sul. Revista Insignare Scientia-RIS, 3(1), 42-56. https://doi.org/10.36661/2595$4520.2020 \mathrm{v} 3 \mathrm{i} 1.11018$

Silva, S. M., \& Rosa, A. R. (2021). O impacto da COVID-19 na saúde mental dos estudantes e o papel das instituições de ensino como fator de promoção e proteção. Revista Prâksis, 2, 189-206. https://doi.org/10.25112/rpr.v2i0.2446

Souza, D. G., \& Miranda, J. C. (2020). Desafios da implementação do ensino remoto. Boletim de Conjuntura (BOCA), 4(11), 81-89. https://doi.org/10.5281/zenodo.4252805

Vieira, K. M., Postiglioni, G. F., Donaduzzi, G., dos Santos Porto, C., \& Klein, L. L. (2020). Vida de estudante durante a pandemia: isolamento social, ensino remoto e satisfação com a vida. EaD em Foco, 10(3), e1147. https://doi.org/10.18264/eadf.v10i3.1147 